\title{
Complementation analysis in patients with the clinical phenotype of a generalised peroxisomal disorder
}

\author{
Steven J Steinberg, Anthony H Fensom
}

\begin{abstract}
The generalised peroxisomal disorders (GPDs) Zellweger syndrome (ZS), neonatal adrenoleucodystrophy (NALD), and infantile Refsum's disease (IRD) are autosomal recessive disorders associated with a failure to assemble mature peroxisomes. We confirmed the diagnosis of a GPD in eight ZS and four IRD patients (GPD1 to GPD12) biochemically by measuring very long chain fatty acids, plasmalogen biosynthesis, and catalase solubility in skin fibroblasts. One further patient (BOX-1) had the clinical phenotype of ZS, but biochemical investigations indicated an isolated deficiency of peroxisomal $\beta$ oxidation. To date a total of 10 complementation groups (CGs) for the GPDs and three further CGs for isolated $\beta$ oxidation deficiencies have been identified. Most GPD patients have been shown to belong to CG1 (Baltimore classification); among the rarer groups, CG-4 and CG-8 predominate. We performed somatic cell hybridisation experiments on strains GPD-1 to GPD-12 using plasmalogen biosynthesis as a marker for correction and found that six ZS and three IRD patients, eight of whom were of UK origin, belonged to CG1. Strain GPD-11, a patient of UK origin with an unusual biochemical phenotype, belonged to CG-8. Strains GPD-10 and GPD-12 were derived from $Z S$ patients of Arabian and Pakistani origin and belonged to the rarer CGs 2 and 7, respectively. Furthermore, complementation analysis using $\beta$ oxidation as a marker showed that BOX-1 had an isolated deficiency of the bifunctional protein.

(f Med Genet 1996;33:295-299)
\end{abstract}

Key words: generalised peroxisomal disorder; peroxisomal bifunctional protein; PXR1.

Division of Medical and Molecular Genetics, United Medical and Dental Schools of Guy's and St Thomas's Hospitals, 7th/8th floors, Guy's Hospital Tower, London Bridge, London SE1 9RT, UK

S J Steinberg

A $\mathrm{H}$ Fensom

Correspondence to: Dr Fensom.

Received 13 April 1995 Revised version accepted

for publication

for publication
$\mathrm{ZS}$ is the most severe disorder and is a polymalformative condition which affects the development of the brain, liver, kidneys, and skeleton. Affected neonates have severe neuro- logical and hepatic dysfunction from birth and often die before 1 year of age. NALD and IRD have a milder and more variable clinical phenotype. $^{1}$

Tissues from GPD patients exhibit a multiplicity of biochemical abnormalities owing to the primary aberration in peroxisome assembly. These include deficiencies in very long chain fatty acid (VLCFA) $\beta$ oxidation, plasmalogen biosynthesis, phytanic acid $\alpha$ oxidation, pipecolic acid oxidation, and bile acid synthesis. ${ }^{1}$ However, some patients with the clinical phenotype of a GPD have been found to have an isolated deficiency of one of three proteins required for peroxisomal $\beta$ oxidation. ${ }^{2-4}$ Patients having isolated deficiencies of acyl $\mathrm{CoA}$ oxidase (ACoAOx) or the bifunctional protein (BP) can be characterised by complementation analysis. ${ }^{5}$

Somatic cell hybridisation studies using human GPD skin fibroblasts have been performed by several laboratories in order to ascertain how many genes are involved in peroxisome biogenesis. To date 10 GPD complementation groups (CGs) have been documented. ${ }^{67}$ In this paper we use the CG nomenclature introduced by investigators in Baltimore. $^{6}$

The results of hybridisation studies reported by Moser $e t ~ a l^{7}$ indicate that essentially three tiers of GPD CGs exist: CG-1 comprised the most patients and all three clinical phenotypes are represented; CG- 4 and CG- 8 have an intermediate representation and clinical heterogeneity is observed within both groups; the remaining CGs are rare and generally contain patients with more severe clinical phenotypes. ${ }^{7}$ The clinical heterogeneity observed among GPD patients is not resolved by a direct correlation between different clinical phenotypes and specific CGs. Similarly, heterogeneity is observed within individual CGs with respect to biochemical function and defects in peroxisomal matrix protein import. ${ }^{89}$ Furthermore, it is possible that CG-1 involves more than one gene product and is an example of non-allelic non-complementation. ${ }^{1011}$ To date, only two genes have been unequivocally associated with two of the rarer groups, CG-2 and CG-10. ${ }^{1213}$

Since biochemical characterisation and complementation analysis are prerequisites for the more precise molecular characterisation of patients having a GPD clinical phenotype, we have undertaken this in 13 patients referred to our laboratory in whom preliminary plasma metabolites indicated such a disorder. We 
measured VLCFA content, plasmalogen biosynthesis, and catalase solubility in cultured fibroblasts from these patients and then carried out somatic cell hybridisation to assign them to a CG. Using plasmalogen biosynthesis as a marker for correction, we found that 12 patients with a GPD could be assigned to a known CG. In addition, using peroxisomal $\beta$ oxidation as a marker for correction we characterised the enzyme defect in one further patient who exhibited an isolated deficiency of VLCFA catabolism.

\section{Methods}

\section{MATERIALS}

The following materials were obtained from the listed sources: ICN Flow: Eagle's minimum essential medium with Earle's salts (EMEM), fetal bovine serum (FBS); Sigma: Ficoll 400, $\left[1-{ }^{14} \mathrm{C}\right]$-hexadecanol $(7 \cdot 7 \mathrm{mCi} / \mathrm{mmol})$; Merck: polyethyleneglycol (PEG) 4000, digitonin; BDH: Giemsa stain; Rathburn: HPLC grade solvents; Professor F Paltauf (Graz, Austria): $1-O-\left[9,10-{ }^{3} \mathrm{H}_{2}\right]$-hexadecylglycerol $(2 \cdot 31 \mathrm{Ci} /$ mmol); Amersham International: $\left[1-{ }^{14} \mathrm{C}\right]$-palmitic acid $(60 \mathrm{mCi} / \mathrm{mmol})$; American Radiolabelled Chemicals: $\left[1-{ }^{14} \mathrm{C}\right]$-lignoceric acid $(55 \mathrm{mCi} / \mathrm{mmol})$.

\section{SOURCE AND MAINTENANCE OF CULTURED}

CELLS

Skin fibroblast strains from 13 unrelated patients with the clinical phenotype of a GPD were available in the Division's cell bank. Ten patients had been diagnosed in our laboratory, one (GPD-10) was diagnosed in Dr Wanders' laboratory (Amsterdam, The Netherlands), and two strains (GPD-5 and GPD-8) were donated for research purposed by Dr P Clayton (ICH, London). Three strains (GPD-3, -7, and -12) were fetal lines obtained after termination of pregnancy in at risk families from which cells from the index case were not available. We received the generous gift of cell strains for GPD CGs 2, 3, 4, 6, 7, and 8 and strains with isolated deficiencies of peroxisomal $\beta$ oxidation enzymes ACoAOx and BP from A Moser (Kennedy Krieger Institute, USA). We used two cell lines (GM6256 (GPD CG-1)

Table 1 Skin fibroblast biochemical parameters

\begin{tabular}{|c|c|c|c|c|}
\hline \multirow[t]{2}{*}{ Cell strains } & \multicolumn{2}{|c|}{ Very long chain fatty acids } & \multirow{2}{*}{$\begin{array}{l}\text { Plasmalogen } \\
\text { Biosynthesis } \\
\left.{ }^{[} \mathrm{H}\right] / I^{14} \mathrm{Cl}\end{array}$} & \multirow{2}{*}{$\begin{array}{l}\text { Catalase } \\
\text { solubility } \\
(\%)\end{array}$} \\
\hline & $C 26: 0(\mu g / m g)$ & $C 26: 0 / C 22: 0$ & & \\
\hline Controls & $\begin{array}{l}0 \cdot 116(\mathrm{SD} 0 \cdot 036) \\
(\mathrm{n}=12)\end{array}$ & $\begin{array}{l}0.110(\mathrm{SD} 0.037) \\
(\mathrm{n}=12)\end{array}$ & $\begin{array}{l}0.5(\text { SD } 0.05) \\
(n=14)\end{array}$ & $\begin{array}{l}18(\mathrm{SD} 6 \cdot 8) \\
(\mathrm{n}=12)\end{array}$ \\
\hline GPD-1 & $0 \cdot 267$ & 0.578 & $7 \cdot 9$ & 83 \\
\hline GPD-2 & 0.346 & $0 \cdot 783$ & $3 \cdot 2$ & 78 \\
\hline GPD-3 & 1.631 & 2.513 & $6 \cdot 1$ & 89 \\
\hline GPD-4 & 0.681 & 0.496 & $4 \cdot 5$ & 81 \\
\hline GPD-5 & 0.633 & 0.467 & 6.9 & 74 \\
\hline GPD-6 & 0.444 & 0.795 & $9 \cdot 4$ & 85 \\
\hline GPD-7 & $1 \cdot 162$ & $1 \cdot 440$ & $9 \cdot 7$ & 77 \\
\hline GPD-8 & 0.631 & 0.292 & $2 \cdot 1$ & 71 \\
\hline GPD-9 & 0.645 & $1 \cdot 150$ & $4 \cdot 7$ & 92 \\
\hline GPD-10 & 0.842 & 0.852 & $1 \cdot 2$ & 76 \\
\hline GPD-11 & 0.320 & 0.876 & $4 \cdot 9$ & 77 \\
\hline GPD-12 & $1 \cdot 145$ & $1 \cdot 776$ & $27 \cdot 7$ & 78 \\
\hline BOX-1 & 0.649 & 1.049 & 0.7 & 8 \\
\hline
\end{tabular}

Results for VLCFA content, plasmalogen synthesis, and catalase solubility are shown for the control and 13 mutant fibroblast strains investigated. and GM6231 (GPD CG-9)) from the Human Genetic Mutant Cell Repository (Camden, NJ) based upon information provided by $\mathrm{A}$ Moser. Cells were maintained up to the 25 th passage in $10 \%$ FBS-EMEM as previously described. ${ }^{14}$

\section{SOMATIC CELL HYBRIDISATION}

Strains paired for hybridisation were co-cultivated, fused with PEG $(42 \%, w / v)$, and separated into two fractions on a Ficoll gradient as previously described. ${ }^{14}$ Fraction II contained predominantly multinuclear cells; fraction I contained mononuclear cells and represented a co-cultivation analysis of the two mutant cell strains. The median fusion index (\% nuclei in multinuclear cells) was $97 \%$ for fraction II and $5 \cdot 5 \%$ for fraction $\mathrm{I}$.

\section{PLASMALOGEN BIOSYNTHESIS}

Cell monolayers incubated for 18 hours in medium containing $0.8 \mu \mathrm{Ci} 1-O-\left[9,10-{ }^{3} \mathrm{H}_{2}\right]$ hexadecylglycerol and $0 \cdot 2 \mu \mathrm{Ci}\left[1-{ }^{14} \mathrm{C}\right]$-hexadecanol were processed as described by Roscher et al..$^{15}$ Final results were expressed as a ratio of the percentage incorporation of each radiolabelled substrate into plasmalogens: $\%\left[{ }^{3} \mathrm{H}\right] / \%\left[{ }^{14} \mathrm{C}\right]$. A ratio $\geq 1$ was indicative of an impairment in the peroxisomal enzymes required for plasmalogen synthesis.

\section{VERY LONG CHAIN FATTY ACIDS}

The concentration of $\mathrm{C} 26: 0$ and the $\mathrm{C} 26: 0 /$ C22:0 ratio of cultured fibroblasts were determined by gas liquid chromatography as described by Moser and Moser. ${ }^{16}$

\section{CATALASE SOLUBILITY}

A supernatant and pellet fraction were isolated from fibroblasts suspended in digitonin-buffer and catalase activity was determined spectrophotometrically. Final results were expressed as the \% solubility (that is, catalase activity in the supernatant fraction/total catalase activity). ${ }^{17}$

\section{PEROXISOMAL $\beta$ OXIDATION}

Suspensions of cultured fibroblasts were incubated for one hour in the presence of $5 \mathrm{nmol}$ $(0.05 \mu \mathrm{Ci})$ of $\left[1-{ }^{14} \mathrm{C}\right]$-palmitic acid or $\left[1-{ }^{14} \mathrm{C}\right]-$ lignoceric acid to compare mitochondrial and peroxisomal fatty acid catabolism. ${ }^{18}$

\section{Results}

\section{BIOCHEMICAL DATA}

Preliminary diagnosis of a peroxisomal disorder was made by measuring VLCFA in plasma or dihyrodroxyacetone phosphate:acyltransferase activity in leucocytes or both. The more definitive diagnosis of a disorder affecting peroxisome assembly was confirmed by measuring three parameters in cultured skin fibroblasts: VLCFA levels, plasmalogen biosynthesis, and catalase solubility. The results from these investigations are shown in table 1 . Twelve 


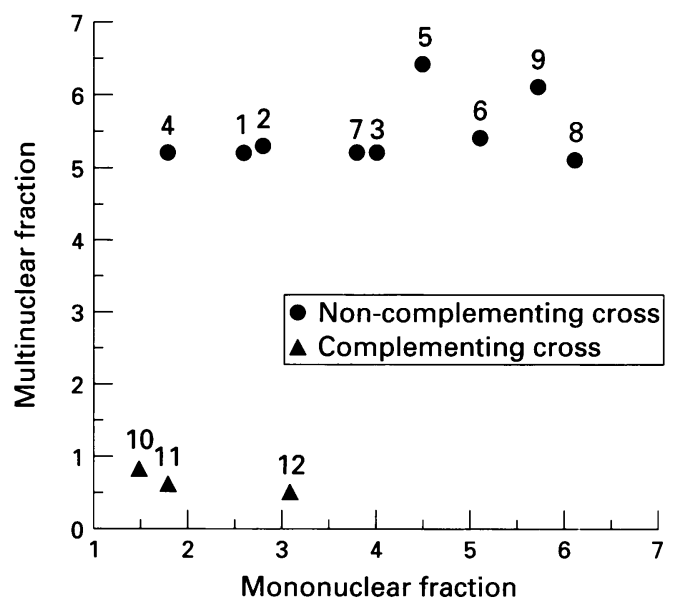

CG-1 crosses for GPD-1 to GPD-12. All GPD strains tested were crossed initially against a known CG-1 strain. The plasmalogen biosynthesis results obtained for each cross have been plotted with the mononuclear cocultivation fraction (I) on the $x$ axis and the multinuclear fraction (II) on the $y$ axis. Strains which did not complement with the known CG-1 strain have a [ $\mathrm{H}$ ]/ $\left[{ }^{14} \mathrm{C}\right]>1$ in fraction II; strains which did complement with the known $C G-1$ strain have a $\left[{ }^{3} \mathrm{H}\right] /\left[{ }^{14} \mathrm{C}\right]<1$ in fraction II. The GPD strain number is indicated above each symbol.

patients (GPD-1 to GPD-12) exhibited multiple deficiencies characteristic of a GPD, but one patient (BOX-1) exhibited an isolated aberration of VLCFA catabolism.

\section{COMPLEMENTATION ANALYSIS}

Each GPD strain was crossed against a known CG-1 strain. The figure shows that nine of the strains (GPD-1 to GPD-9) crossed against a known CG-1 stain did not show a correction of plasmalogen biosynthesis, indicating that they belong to CG-1. In contrast, multinuclear cells derived from strains GPD-10, -11 and -12 exhibited a $\left[{ }^{3} \mathrm{H}\right] /\left[{ }^{14} \mathrm{C}\right]$ ratio within the normal

Table 2 Complementation analysis in fibroblast strains that did not belong to CG-1

\begin{tabular}{lllll}
\hline \multirow{2}{*}{ Unclassified GPD patients } & \multicolumn{4}{l}{ Classified GPD complementation groups } \\
\cline { 2 - 5 } & & $C G-2$ & $C G-7$ & $C G-8$ \\
\hline & {$\left[{ }^{3} \mathrm{H}\right] /\left[{ }^{14} \mathrm{C}\right]$} & $18 \cdot 5$ & $1 \cdot 3$ & $5 \cdot 9$ \\
GPD-10 & $1 \cdot 2$ & $1 \cdot 3 / 1 \cdot 1$ & $0 \cdot 4 / 1 \cdot 0$ & $0 \cdot 7 / 1 \cdot 4$ \\
GPD-11 & $4 \cdot 9$ & $\mathrm{~nm}$ & $\mathrm{~nm}$ & $3 \cdot 4 / 2 \cdot 7$ \\
GPD-12 & $27 \cdot 7$ & $0 \cdot 4 / 6 \cdot 3$ & $2 \cdot 4 / 2 \cdot 0$ & $0 \cdot 4 / 1 \cdot 8$ \\
\hline
\end{tabular}

Non-CG-1 GPD strains were initially hybridised with strains representative of CG-4 and CG8. Only strains GPD-10 and GPD-12 needed to be crossed with strains from the eight CGs available to us. Plasmalogen biosynthesis results are shown only for crosses with the three nonCG-1 strains associated with our patients. The $\left[{ }^{3} \mathrm{H}\right] /\left[{ }^{14} \mathrm{C}\right]$ ratio is shown for wich the three nonand results for each cross are expressed as a ratio of fraction $\mathrm{II} /$ fraction $\mathrm{I}$ (nm=not measured).

Table 3 Complementation analysis by $\beta$ oxidation measurement

\begin{tabular}{|c|c|c|c|c|c|c|}
\hline \multicolumn{4}{|l|}{ Cell strains } & \multicolumn{3}{|c|}{$C 24: 0 / C 16: 0$} \\
\hline Strain 1 & & Strain 2 & & $F \times I I$ & $F x I$ & $F x I I / F x I$ \\
\hline $\begin{array}{l}\text { BOX-1 } \\
\text { BOX-1 } \\
\text { BOX-1 } \\
\text { Control-1 } \\
\text { Control-2 }\end{array}$ & $\begin{array}{l}(0.12) \\
(0.12) \\
(0.12) \\
(0.69) \\
(0.90)\end{array}$ & $\begin{array}{l}\text { GPD-3 } \\
\text { BP-1 } \\
\text { ACoAOx-1 } \\
- \\
-\end{array}$ & $\begin{array}{l}(0.06) \\
(0.05) \\
(0.08)\end{array}$ & $\begin{array}{l}0.532 \\
0.052 \\
0.444\end{array}$ & $\begin{array}{l}0.042 \\
0.053 \\
0.117\end{array}$ & $\begin{array}{r}12 \cdot 7 \\
1 \cdot 0 \\
3 \cdot 8\end{array}$ \\
\hline
\end{tabular}

Results for three crosses using $\beta$ oxidation as a marker for correction are shown. Baseline C24: 0/C16:0 oxidation ratios are shown in parentheses beside each parental mutant strain and two control strains. Final results for each cross are expressed as a ratio of fraction II/fraction I. A ratio significantly greater than 1 indicated that correction of the baseline defect had occurred. BOX-1 complemented a CG-1 GPD strain and a mutant strain with ACoAOx deficiency, but CoA oxidase). control range when crossed with CG-1 cells. In each case we were able to identify a strain from another CG which did not complement the three non-CG-1 strains (table 2). Strains GPD-10, -11 , and -12 belonged to CG-2, CG8 , and CG-7, respectively.

Fibroblasts from the patient BOX-1 were hybridised with cells from patients with defined defects in the peroxisomal $\beta$ oxidation enzymes ACoAOx and BP. The C24:0/C6:0 oxidation ratios in table 3 indicate that $\mathrm{BOX}-1$ had an isolated deficiency of the BP.

Table 4 summarises the complementation results and lists the clinical phenotypes observed in the patients in our study. GPD CG1 contained five classic ZS, one long surviving ZS with Leber's congenital amaurosis presentation, and three IRD patients. Two ZS and one IRD patients belong to the rarer GPD CGs. Furthermore, one patient with a severe clinical phenotype had an isolated deficiency of the BP. In addition, table 4 shows that nine of the patients studied were of UK origin and that eight of these patients belonged to GPD CG-1. Only one patient of UK origin, GPD11 , belonged to one of the rarer GPD CGs.

\section{Discussion}

Our finding that the majority (nine of 12) of the GPD patients we investigated belong to CG-1 was not unexpected in the light of results reported by other investigators. Clinical heterogeneity was observed within CG-1 patients, but no NALD patients were among those studied. The absence of NALD patients in our study may be the result of a referral bias, since one of our major referral sources includes a paediatric liver unit providing a national service, while our paediatric neurological referrals are from a more local population. Furthermore, these clinical labels are not universally agreed upon and assigning patients to specific phenotypes is therefore subject to interpretation. The important point is that the majority of patients investigated had a severe, early onset disorder.

Nine of the GPD patients investigated were of UK origin: eight belonged to CG-1 and one belonged to CG-8. Consequently, all of the patients of UK origin belonged to one of the three principal groups (CG-1, -4 , and -8). This may be a reflection of the homogeneity of the population living in Britain. GPD-10 and GPD-12 belonged to rare CGs and come from Arabian and Pakistani backgrounds; larger studies may in time show an association between GPD CGs and particular ethnic groups, which would be of benefit for more rapid characterisation of the underlying defect.

None of the patients in this study had a variant clinical phenotype, although CG-1 patient GPD-2 was a case of long surviving ZS. The CG-8 IRD patient GPD-11 had an atypical biochemical phenotype, which has been described previously. ${ }^{19}$ In the CG-2 patient GPD-10, there was early, severe onset of hepatic and neurological dysfunction together with classic dysmorphic facial features and we have therefore classified her as ZS although we 
Table 4 Summary of complementation results for the patients studied

\begin{tabular}{|c|c|c|c|c|c|c|c|}
\hline \multirow[t]{3}{*}{$C G$ identification } & \multirow{3}{*}{$\begin{array}{l}\text { Total no of } \\
\text { patients }\end{array}$} & \multicolumn{2}{|c|}{ Sex } & \multicolumn{4}{|c|}{ Clinical phenotype } \\
\hline & & \multirow[t]{2}{*}{$M$} & \multirow[t]{2}{*}{$F$} & \multicolumn{2}{|c|}{ Zellweger syndrome } & \multicolumn{2}{|c|}{ Infantile Refsum's disease } \\
\hline & & & & $U K$ origin & Other origin & $U K$ origin & Other origin \\
\hline GPD CG-1 & 9 & 2 & 7 & $5^{*}$ & 1 & 3 & 0 \\
\hline GPD CG-2 & 1 & 0 & 1 & 0 & 1 & 0 & 0 \\
\hline GPD CG-7 & 1 & 1 & 0 & 0 & 1 & 0 & 0 \\
\hline GPD CG-8 & 1 & 1 & 0 & 0 & 0 & $1 \dagger$ & 0 \\
\hline BP deficiency & 1 & 1 & 0 & 0 & 1 & 0 & 0 \\
\hline
\end{tabular}

The number of patients belonging to the GPD CGs according to the Baltimore nomenclature are shown. Patients are classified according to the clinical phenotypes ZS and IRD. "UK origin" indicates a person born in the UK who is not a member of a specific ethnic group. ${ }^{*}$ One long surviving ZS patient in this group. † Patient A in Steinberg et al. ${ }^{19}$

do not know if there was calcific stippling of the patellae.

The cell strain GPD-12, which belongs to CG-7, was a fetal strain obtained after a positive prenatal diagnosis. Necropsy of this fetus of 22-23 weeks' gestation showed hypoplastic adrenal glands, dysmorphic facies, and anal atresia. In the cortex of the kidneys there were a few cystically dilated tubules, and occasional dilating collecting ducts in the medulla. There was cardiomegaly and the right ventricle was much larger than the left, the ratio being 0.75 : $0 \cdot 25$. Both ventricles had very thick muscular walls. The pulmonary trunk was dilated and was wider than the ascending aorta. Both great vessels issued from the right ventricle and there was a ventricular septal defect. The right lung had only two lobes and the left lung a single lobe. A previously affected sib, who was not studied biochemically, died at the age of 4 months with a history of liver problems, metaphyseal skeletal changes, a large anterior fontanelle, and, on necropsy, was found to have renal cysts. A further sib died within the first day of life in Pakistan for reasons which are unclear.

The incentive to characterise the molecular defects in these patients is increased by our inability to detect carriers for GPDs biochemically. ${ }^{1}$ This classification strategy has already proven itself useful for GPD-10, who belonged to CG-2. Dodt et al ${ }^{13}$ recently described mutations in PXR1, a gene which encodes a peroxisomal targeting signal (PTS) type 1 receptor, in two CG-2 patients. ${ }^{13}$ Immunocytochemical studies have indicated that GPD10 (PBD093 in Slawecki et $a l^{9}$ ) exhibits a PTS type 1 import defect. This patient is homozygous for a $T \rightarrow G$ transversion at bp 1467 of the PXR1 allele, producing an Asn489Lys substitution (S Gould, personal communication). This mutation is identical to the one described by Dodt et $a l^{13}$ for patient PBD018. The biochemical phenotypes expressed in skin fibroblasts from each patient were similar: a marked accumulation of VLCFA, a profound deficiency of phytanic acid oxidation, but only a marginal deficiency in plasmalogen biosynthesis (A Moser, personal communication). It is of interest that both PBD018 and GPD-10 are of Arabian origin; currently we have no evidence that these patients are related.

Patient BOX-1 had a severe clinical phenotype, but complementation analysis indicated that this patient had an isolated deficiency of the BP. The gene for the BP has been cloned ${ }^{20}$ and we have requested that this patient be investigated for disease causing mutations.

In summary, the 13 patients investigated belonged to previously described CGs. Characterisation of the molecular defect has been achieved in only one patient (GPD-10), but should be attained in the near future in one further patient (BOX-1). Characterisation of the remaining patients at a molecular level will depend upon the speed at which further genes required for peroxisome assembly in the human are cloned.

We are indebted to Ann and Hugo Moser for their generosity in supplying cell lines; Stephen Gould and his colleagues for their studies on strain GPD-10; Tina Slade and Ronayne Grant for assistance in cell culture and preliminary diagnosis of some
GPD patients; Mary Seller for the fetal postmortem study; and GPD patients; Mary Seller for the fetal postmortem study; and
Adrienne Knight for preparation of the manuscript. We extend our appreciation to Peter Clayton and all of the other physicians who referred patients for study. This work has been funded by LORS

1 Lazarow PB, Moser HW Disorders of peroxisome biogenesis. In: Scriver CR, Beaudet AL, Sly WS, Valle D, genesis. In: Scriver CR, Beaudet AL, Sly WS, Valle D, eds. The metabolic and molecular basis of in

2 Poll-The BT, Roels F, Ogier H, et al. A new peroxisomal disorder with enlarged peroxisomes and a specific deficiency of acyl-CoA oxidase (pseudo-neonatal adrenoleukodystrophy). Am $\mathcal{F}$ Hum Genet 1988;42:422-34.

3 Watkins PA, Chen WW, Harris CJ, et al. Peroxisomal bifunctional enzyme deficiency. $\mathcal{f}$ Clin Invest 1989;83:77177 .

4 Schram SW, Goldfischer S, van Roermund CWT, et al. Human peroxisomal 3-oxoacyl-coenzyme A thiolase deficiency. Proc Natl Acad Sci USA 1987;84:2494-6.

5 McGuiness MC, Moser AB, Poll-The BT, Watkins PA. Complementation analysis of patients with intact peroxisomes and impaired peroxisomal $\beta$ oxidation. Biochem Med Metab Biol 1993;49:228-42.

6 Shimozawa N, Sizuki Y, Orii T, et al. Standardization of complementation grouping of peroxisome deficient disorders and the second Zellweger syndrome patient with peroxisomal assembly factor-1 (PAF-1) defect. Am $\mathcal{F} \mathrm{Hum}$ Genet 1993;52:843-4

7 Moser AB, Rasmussen M, Naidu S, et al. Phenotype of 173 peroxisome disorder patients subdivided into $16 \mathrm{com}$ plementation groups. $\mathcal{F}$ Pediatr $1995 ; 127: 13-22$.

8 Wiemer EAC, Out M, Schelen A, et al. Phenotypic heterogeneity in skin fibroblasts from patients with disorders of peroxisome biogenesis belonging to the same complementation group. Biochim Biophys Acta 1991;1097:2327.

9 Slawecki ML, Dodt G, Steinberg S, et al. Identification of three distinct peroxisomal protein import defects in patients with peroxisome biogenesis disorders. $\mathcal{f}$ Cell Sci patients with peroxis

10 Gärtner J, Moser H, Valle D. Mutations in the $70 \mathrm{~K}$ peroxisomal membrane protein gene in Zellweger syndrome. oxisomal membrane protein

11 Braverman N, Dodt G, Gould SJ, Valle D. Disorders of Braverman N, Dodt G, Gould SJ, Valle D. Disorders of

12 Tsukamoto T, Miura S, Fujiki Y. Restoration by a $35 \mathrm{~K}$ membrane protein of peroxisome assembly in a permembrane protein of peroxisome assembly in a per350:77-81.

13 Dodt G, Braverman N, Wong C, et al. Mutations in the PTS 1 receptor gene, PXR1, define complementation group 2 in the peroxisome biogenesis disorders. Nature Genet 1995 9:115-25.

14 Steinberg SJ, Ward CP, Fensom AH. Complementation studies in Niemann-Pick disease type $\mathrm{C}$ indicate the existence of a second group. $\mathcal{f}$ Med Genet 1994;31:317-20. 
15 Roscher A, Molzer B, Bernheimer $\mathrm{H}$, et al. The cerebrohepatorenal (Zellweger) syndrome: an improved method for the biochemical diagnosis and its potential
value for prenatal detection. Pediatr Res 1985;19:930-3.

16 Moser HW, Moser AB. Measurement of saturated very long chain fatty acids in plasma. In: Hommes FA, ed. Techniques in diagnostic human biochemical genetics. New York: WileyLiss, 1991:177-92.

17 Lazarow PB, Fujiki Y, Small GM, Watkins P, Moser H. Presence of the peroxisomal $22-\mathrm{kDa}$ integral membrane protein in the liver of a person lacking recognizable peroxisomes (Zellweger syndrome). Proc Natl Acad Sci USA 1986;83:9193-6.
18 Watkins PA, Ferrell EV, Pederson JI, Hoefler G. Peroxisomal fatty acid $\beta$ oxidation in HepG 2 cells. Arch Biochem Biophys $1991 ; 289 \cdot 329-36$.

19 Steinberg SJ, Fensom AH, Dalton NR, et al. Measurement of plasma very long-chain fatty acids as a preliminary screening procedure for the diagnosis of peroxisomal disorders. F Inher Metab Dis 1994;17:323-6.

20 Hoefler G, Forstner M, McGuiness MC, et al. cDNA cloning of the human peroxisomal enoyl-CoA hydratase: 3-hydroxyacyl-CoA dehydrogenase bifunctional enzyme and localization to chromosome 3q26.3-3q28: a free left Alu arm is inserted in the $3^{\prime}$ noncoding region. Genomics 1994;19:60-7. 